\title{
Limited evidence of intercontinental dispersal of avian paramyxovirus serotype 4 by migratory birds
}

Andrew B. Reeves ${ }^{\mathrm{a},{ }^{*}}$, Rebecca L. Poulson ${ }^{\mathrm{b}}$, Denys Muzyka ${ }^{\mathrm{c}}$, Haruko Ogawa ${ }^{\mathrm{d}}$, Kunitoshi Imai $^{\mathrm{d}}$, Vuong Nghia Bui ${ }^{\mathrm{d}}$, Jeffrey S. Hall ${ }^{\mathrm{e}}$, Mary Pantin-Jackwood ${ }^{\mathrm{f}}$, David E. Stallknecht ${ }^{\mathrm{b}}$, Andrew M. Ramey ${ }^{\mathrm{a}, *}$

${ }^{a}$ US Geological Survey, Alaska Science Center, 4210 University Drive, Anchorage, Alaska 99508, USA

${ }^{\mathrm{b}}$ Southeastern Cooperative Wildlife Disease Study, The University of Georgia, 589 D. W. Brooks Drive, Athens, Georgia 30602, USA

${ }^{\mathrm{c}}$ National Scientific Center Institute of Experimental and Clinical Veterinary Medicine, Pushkinska Street 83, Kharkiv, Ukraine, 61023

${ }^{\mathrm{d}}$ Diagnostic Center for Animal Health and Food Safety, Obihiro University of Agriculture and Veterinary Medicine, 2-11 Inada, Obihiro, Hokkaido 080-8555, Japan

${ }^{\mathrm{e}}$ US Geological Survey, National Wildlife Health Center, 6006 Schroeder Road, Madison, Wisconsin 53711, USA

${ }^{\mathrm{f}}$ Southeast Poultry Research Laboratory, U.S. National Poultry Research Center, U.S. Department of Agriculture, Agricultural Research Service, Athens, Georgia 30677, USA *Corresponding authors

E-mail address: aramey@usgs.gov (A. Ramey)

E-mail address: areeves@usgs.gov (A. Reeves) 


\begin{abstract}
Avian paramyxovirus serotype $4(\mathrm{APMV}-4)$ is a single stranded RNA virus that has most often been isolated from waterfowl. Limited information has been reported regarding the prevalence, pathogenicity, and genetic diversity of AMPV-4. To assess the intercontinental dispersal of this viral agent, we sequenced the fusion gene of 58 APMV-4 isolates collected in the United States, Japan and the Ukraine and compared them to all available sequences on GenBank. With only a single exception the phylogenetic clades of APMV-4 sequences were monophyletic with respect their continents of origin (North America, Asia and Europe). Thus, we detected limited evidence for recent intercontinental dispersal of APMV-4 in this study.
\end{abstract}

Keywords: avian paramyxovirus serotype 4; dispersal, intercontinental; migratory bird 


\section{Introduction}

Evidence supports the intercontinental dispersal of bacterial, viral, and parasitic agents by migratory birds. For example, seabirds may play a role in the transhemispheric exchange of the bacteria Borrelia garrinii (Olsen et al., 1995). Avian influenza viruses (AIV), avian paramyxovirus serotype 1 (APMV-1), eastern equine encephalitis virus, Sindbis virus, and West Nile virus may be dispersed between continents by a variety of avian taxa (Calisher et al., 1971; Lundstrom and Pfeffer, 2010; Malkinson et al., 2002; Ramey et al., 2013; Ramey et al., 2015a). Similarly, migratory birds may facilitate the intercontinental exchange of ticks, trematodes, and blood parasites (Hoogstraal et al., 1963; Levin et al., 2013; Ramey et al., 2015b; Smith and Ramey, 2015; Tallman et al., 1985; Wallmenius et al., 2014). Thus, there is a growing body of literature supporting a routine exchange of infectious agents between regions by migratory birds and the potential for identifying patterns of dispersal that may be useful to predict the spread of emerging avian pathogens.

Relative to many other viral agents infecting avian species (e.g., APMV-1 and AIV), relatively little research has been conducted regarding the epidemiology and genetics of avian paramyxovirus serotype 4 (APMV-4). APMV-4 is one of 12 serotypes of avian paramyxoviruses (Gogoi et al., 2015), all of which are classified in the genus Avulavirus, characterized as having negative-sense single-stranded RNA that upon transcription encodes for six proteins: nucleocapsid protein $(\mathrm{N})$, a phosphoprotein $(\mathrm{P})$, a matrix protein $(\mathrm{M})$, a fusion glycoprotein (F), a hemagglutinin-neuraminidase glycoprotein (HM), and a large polymerase protein (L) (Gogoi et al., 2015; Zohari, 2013). APMV infections primarily concentrate in epithelial cells of the avian host's respiratory and gastrointestinal tracts (Zohari, 2013). Although the full range of hosts for APMV-4 is unknown, these viruses are isolated most often 
from wild waterfowl hosts with infections also detected in domestic ducks, geese and occasionally in chickens (Zohari, 2013). The pathogenic impact of APMV-4 infection on avian hosts is largely unknown; however, disease has not been reported for birds from which viruses have been isolated and experimental inoculation produced no clinical signs in specific pathogen free chickens despite the presence of microscopic lesions in the trachea, lungs, and viscera (Warke et al., 2008). For APMV-1, virulence is linked to specific mutations in the F protein sequence (de Leeuw et al., 2003; de Leeuw et al., 2005; Panda et al., 2004; Peeters et al., 1999), a characteristic that makes $\mathrm{F}$ sequences a commonly used marker in phylogenetic studies for this and other serotypes (Diel et al., 2012; Miller et al., 2009; Ramey et al., 2013). While genetic diversity of APMV-4 has been explored using field isolate F gene sequences from South Korea and Italy (Choi et al., 2013; Nayak et al., 2013), genetic information for viruses originating from North America (Parthiban et al., 2013) and Africa (Abolnik et al., 2012) has been limited to only a single strain from each continent in the GenBank database as of the time of manuscript preparation. Consequently, information on global phylogeography and dispersal of APMV-4 between continents is limited.

In this study, we obtained genetic sequences for the complete coding region of the fusion gene of APMV-4 isolates obtained from wild birds in Japan, Ukraine, and the United States and compared them to publically available information on GenBank to assess global phylogeny and evidence for the intercontinental dispersal of this viral agent. We predicted that there would be extensive evidence for viral exchange among regions within the Old and New Worlds, with lesser but detectable evidence for interhemispheric viral dispersal between Eurasia and North America, patterns consistent with generalized migratory tendencies of wild birds (Boere and Stroud, 2006) and data for other avian infectious agents such as AIV (Krauss et al., 2007). 
Results of this study build upon the existing body of literature on the potential of migratory birds to disseminate infectious agents across the landscape.

\section{Materials and methods}

During 2005-2014, cloacal, oropharyngeal, and fecal samples were collected from migratory birds in Japan, Ukraine, and the United States as part of multiple independent AIV, and in some instances APMV, surveillance efforts. Swab samples were subjected to virus isolation in embryonated chicken eggs using standard techniques as described in Senne (2008). Twenty isolates originating from samples collected in Japan from 2008-2010, 13 isolates originating from samples collected in Ukraine in 2010-2014, and 25 isolates originating from samples collected in the United States in 2005-2013, were identified as possible APMV-4 strains through serological screening methods (Japan, Ukraine and 2005-2007 USA samples) or molecular (RT-PCR) testing of non-influenza hemagglutinating allantoic fluid (2008-2013 USA samples). Confirmation of APMV-4 was based on genetic sequencing of a partial fragment of the $\mathrm{F}$ gene prior to genetic characterization. Complete protocols and results for isolation and diagnostic tests from specific laboratories are available on request.

Viral RNA was extracted from allantoic fluid using the High Pure Viral RNA Kit (Japan samples; Roche, Indianapolis, IN), QIAamp Viral RNA Mini kit (continental United States samples; Qiagen Inc., Valencia, CA), MagMAX AI/NDV RNA extraction kit (Alaska United States samples; Ambion Inc., Austin, TX) and innuSolv RNA reagent (Ukraine samples; Analytik Jena AG, Jena, Germany). The complete coding region for the fusion gene was sequenced for all 58 APMV-4 isolates using the one-step RT-PCR kit (Qiagen Inc., Valencia, CA). Primers used and the RT-PCR conditions are provided in Table 1. Partial fusion genes 
were previously sequenced for two of the Ukraine (GenBank accession numbers: KF851266-

KF851267; Muzyka et al., 2014) and 18 Japan (GenBank accession numbers: KT867035-

KT867036, KT867037-KT867053; Bui et al., unpublished) isolates. All 20 of these isolates were further sequenced as a part of this study to complete the coding region sequences of the fusion gene. PCR products were purified using a QIAquick Gel Extraction Kit (Qiagen Inc., Valencia, CA) or with ExoSap-IT (USB Inc., Cleveland, OH) without additional purification prior to sequencing. Cycle sequencing was performed with identical primers used for PCR along with BigDye Terminator version 3.1 mix (Applied Biosystems, Foster City, CA). Samples were analyzed on an Applied Biosystems 3730xl automated DNA sequencer (Applied Biosystems, Foster City, CA). Sequences were assembled, edited and translated to study the amino acid motifs of the fusion gene cleavage site with Sequencher version 4.7 (Gene Codes Corp., Ann Arbor, MI). GenBank accession numbers for the complete coding region of fusion genes for APMV-4 isolates sequenced as part of this study are: KT732290-KT732345.

A phylogeny of the complete coding region of the fusion gene was constructed by comparing sequence data for these APMV-4 isolates to all available full length (1,701 nts) sample sequences $(n=11)$ obtained from the GenBank database at the National Center for Biotechnology Information. GenBank acquired sequences were aligned with those generated in this study and cropped using Sequencher version 4.7 (Gene Codes Corp., Ann Arbor, MI). A Maximum Likelihood (ML) tree with 1,000 bootstrap replicates was generated with MEGA version 6.0 (Tamura et al., 2013) using models that best fit the sequence data under the Akaike Information Criterion (AIC; Akaike 1974). Strongly supported clades comprised of APMV-4 fusion gene sequences from multiple continents were interpreted as providing evidence for intercontinental viral dispersal. Conversely, a lack of evidence for the movement of APMV-4 
viruses between continents was inferred if and where continental monophyly was identified in the phylogeny. The mean nucleotide (NT) and translated amino acid (AA) distances between clades were calculated in MEGA6 (Tamura et al., 2013), as the average number of base and amino acid differences per site over all sequence pairs between clades.

\section{Results}

The deduced amino acid motif at the fusion protein cleavage site sequence for all APMV4 isolates sequenced in this study was DIQPR $\downarrow$ F (Suppl. Table 1), consistent with all previously reported APMV-4 strains obtained from GenBank. The ML phylogeny for 69 APMV-4 fusion gene sequences was formed of five major clades (A-B; Fig. 1) that were almost exclusively monophyletic by continent of sample origin. Only sequences for two APMV-4 strains from Asia (APMV-4/Anas sp./Japan/10KI182/2010 and FJ177514 APMV-4/duck/Hong Kong/D3/75) did not fall within these major clades. Clade A was well-supported (bootstrap value of 99) and was comprised of 21 sequences for viruses isolated from ducks sampled in the Asian countries of China, Japan, and South Korea. Clade B also had fairly strong support (bootstrap value of 86) and was made up of 15 sequences of viruses isolated from ducks, geese, and a starling (family Sturnidae) sampled in the European countries of Italy and Ukraine, as well as a single sequence for an APMV-4 strain originating from an Egyptian goose (Alopochen aegyptiaca) sampled in South Africa. Clade C had less support as compared to others (bootstrap support value of 64) and contained four sequences of viruses isolated from mallards (Anas platyrhynchos) sampled in Italy and Belgium. Clades D and E were both well-supported (bootstrap values of 100) and comprised of sequences for viruses originating from waterfowl sampled from the USA. With regard to the two sequences from Asia that were not nested within these five major clades, strain 
APMV-4/Anas sp./Japan/10KI182/2010 was most closely related to Old World clades A-C (bootstrap support value 99) whereas strain APMV-4/duck/Hong Kong/D3/75 was phylogenetically most closely related to North American Clade D (bootstrap support value 100; Fig. 1).

Genetic distances between all clades ranged from $0.024-0.145$ and $0.012-0.049$ for nucleotide and amino acid comparisons, respectively (Fig 1). Analysis revealed the most closely related clades in our dataset for both NT and AA comparisons (A, B and C; 0.024-0.026; and 0.012-0.014, respectively) were those made up of European and Asian samples. The most divergent clade of APMV-4 sequences in our dataset was the North American virus group E, with NT distances of $0.141-0.145$ and AA distances of $0.046-0.049$ to all other clades.

\section{Discussion}

Contrary to results for other viruses frequently isolated from wild birds, we did not find clear evidence for the intercontinental dispersal of APMV-4 with the possible exception being a sequence from Africa nested within European Clade B (Fig. 1.). Wild birds migrate among areas in Africa and Europe via the East Atlantic and Black Sea/Mediterranean flyways (Boere and Stroud, 2006) providing a possible mechanism through which APMV-4 may be exchanged between these continents; however, sequence information from Africa was limited to a single viral strain. Therefore additional genetic information would be useful for evaluating the relationship among APMV-4 strains from Africa and further assessing viral exchange between this continent and Europe. Although we did not find evidence for the exchange of APMV-4 between Asia and North America using our criteria, the close phylogenetic relationship between APMV-4/duck/Hong Kong/D3/75 with North American sequences in Clade D may represent 
historical viral movement between these continents (e.g., introduction from Asia to North America). However, additional data for historical viruses are needed to support or refute this possibility. No information was publically available for APMV-4 strains from Oceania or South America for inclusion in this study. Thus, information for APMV-4 strains from these regions is needed to gain inference regarding the relationship among APMV-4 viruses from these southern hemispheric continents and those from Europe, Asia, and North America. Although APMV-4 sequences analyzed in this study almost exclusively formed well-supported clades with strains originating from the same continent (clades A-E), these continental groupings were comprised of sequences from different countries/states supporting regional viral dispersal. Thus, mechanisms limiting intercontinental transport of APMV-4 may not inhibit viral movement at intracontinental spatial scales.

The limited evidence of intercontinental and interhemispheric dispersal of APMV-4 by migratory birds could be a function of sampling efforts to date, duration of viral shedding, and/or numerous other epidemiological factors pertaining to APMV-4 infections in wild birds for which limited or no data currently exist. Unlike viruses such as APMV-1 and AIV for which evidence of intercontinental dispersal by wild birds has been found (Dusek et al., 2014; Ramey et al., 2013; Ramey et al., 2015b; Wille et al., 2014) relatively few sequences have been generated for APMV-4 and their origins are geographically less widespread compared to the hundreds and thousands of strains identified around the world for APMV-1 and AIV respectively. In a study assessing the intercontinental dispersal of APMV-1 via wild birds, Ramey et al. (2013) describe two clades of Class II fusion gene sequences for strains isolated from wild birds in Eurasia and North America. That study, however, included an analysis of a larger sample of 110 full fusion gene sequences for APMV-1 strains isolated from wild birds. If the long distance dispersal of 
APMV-4 and subsequent establishment in local avifauna is a rare event with correspondingly low detection probability, a larger sample of sequences may be needed to find evidence for intercontinental or interhemispheric viral movement.

Additionally, some genetic diversity for APMV-1 appears to have restricted host and/or geographic range (e.g., genotype Va limited primarily to North American cormorants and genotypes XIV and XVII which have only been detected within Africa; Dimitrov et al. (2016)) which may be a function of complex viral ecology. While the current study increased the number of APMV-4 full fusion gene sequences from 11 to 69 , the majority of sequences originated from the United States $(n=26)$, Japan $(n=20)$, and Ukraine $(n=12)$. Thus, the current dataset for APMV-4 may have unrecognized host/geographic biases and isolates originating from more widespread localities, including unrepresented and underrepresented continents (South America, Africa, and Oceania) would strengthen analyses to assess the movement of viruses between continents.

Another explanation for the lack of evidence for intercontinental viral dispersal is that the shedding period for APMV-4 may be sufficiently short such that it provides little opportunity for viral movement over long distances by a single bird. Sequential infections, however, minimize the need for long distance dispersal by a single individual and therefore there may be a more parsimonious explanation. Perhaps other epidemiological factors such as host susceptibility, viral infectivity, or environmental persistence play an important role in determining the geographic extent of APMV-4. Unfortunately, laboratory experiments evaluating host range, transmission, and persistence relative to environmental conditions are currently lacking for APMV-4. 


\section{Acknowledgements}

None of the authors have any financial interests or conflict of interest with this article. Any use of trade names is for descriptive purposes only and does not imply endorsement by the U.S. Government. The collection and isolation of Ukraine samples was performed as part of international projects P-444, P-444a, and P-444b funded by USDA/ARS through the Ukrainian Science and Technology Center. This work was also partially funded by the National Institute of Allergy and Infectious Diseases, National Institutes of Health and Human Services, under contract HHSN272201400006C, by Grant-in-Aid for Exploratory Research (19659115) from the Ministry of Education, Culture, Sports, Science and Technology (MEXT), Japan, and through the U.S. Geological Survey (USGS) through the Ecosystems Mission Area. The funding agencies were not involved in the design, implementation, or publishing of this study and the research presented herein represents the opinions of the authors, but not necessarily the opinions of the funding agencies. This report was reviewed and approved by USGS under the Fundamental Science Practices policy (http://www.usgs.gov/fsp/). This manuscript was improved by comments from J. Pearce, D. Menning, and two anonymous reviewers. 


\section{References}

Abolnik, C., de Castro, M., Rees, J., 2012. Full genomic sequence of an African Avian Paramyxovirus Type 4 strain isolated from a wild duck. Virus Genes 45, 537-541.

Akaike, H., 1974. A New Look at the Statistical Model Identification. IEEE Transactions on Automatic Control 19, 716-723.

Boere, G.C., Stroud, D.A., 2006. The flyway concept: what it is and what it isn't, in: Boere, G.C., Galbraith, C.A., Stroud, D.A. (Eds.), Waterbirds around the world. The Stationary Office, Edinburgh, UK, pp. 40-47.

Bui, V.N., Trinh, D.Q., Jamsransuren, D., Ngo, L.H., Erdenechimeg, D., Ekkahai, K., Thampaisarn, R., Abao, L.N.B., Yamaguchi, E., Baatartsogt, T., Gronsang, D., Saito, K., Watanabe, S., Runstadler, J.A., Ogawa, H., Imai, K., unpublished. Avian paramyxoviruses from migratory water birds in eastern Hokkaido, Japan: Isolation, genetic characterization and evidence of genetic variation.

Calisher, C.H., Maness, K.S., Lord, R.D., Coleman, P.H., 1971. Identification of two South American strains of eastern equine encephalomyelitis virus from migrant birds captured on the Mississippi delta. Am J Epidemiol 94, 172-178.

Choi, K.S., Kim, J.Y., Kye, S.J., Park, C.K., Sung, H.W., 2013. Genetic diversity of avian paramyxovirus type 4 isolates from wild ducks in Korea from 2006 to 2011. Virus Genes 46, 302-308.

de Leeuw, O.S., Hartog, L., Koch, G., Peeters, B.P., 2003. Effect of fusion protein cleavage site mutations on virulence of Newcastle disease virus: non-virulent cleavage site mutants revert to virulence after one passage in chicken brain. J Gen Virol 84, 475-484.

de Leeuw, O.S., Koch, G., Hartog, L., Ravenshorst, N., Peeters, B.P., 2005. Virulence of Newcastle disease virus is determined by the cleavage site of the fusion protein and by both the stem region and globular head of the haemagglutinin-neuraminidase protein. $\mathbf{J}$ Gen Virol 86, 1759-1769.

Diel, D.G., da Silva, L.H., Liu, H., Wang, Z., Miller, P.J., Afonso, C.L., 2012. Genetic diversity of avian paramyxovirus type 1: Proposal for a unified nomenclature and classification system of Newcastle disease virus genotypes. Infect Genet Evol 12, 1770-1779.

Dimitrov, K.M., Ramey, A.M., Qiu, X., Bahl, J., Afonso, C.L., 2016. Temporal, geographic, and host distribution of avian paramyxovirus 1 (Newcastle disease virus). Infect Genet Evol : journal of molecular epidemiology and evolutionary genetics in infectious diseases 39 , 22-34.

Dusek, R.J., Hallgrimsson, G.T., Ip, H.S., Jonsson, J.E., Sreevatsan, S., Nashold, S.W., TeSlaa, J.L., Enomoto, S., Halpin, R.A., Lin, X.D., Fedorova, N., Stockwell, T.B., Dugan, V.G., Wentworth, D.E., Hall, J.S., 2014. North Atlantic migratory bird flyways provide routes for intercontinental movement of avian influenza viruses. PLoS ONE 9.

Gogoi, P., Ganar, K., Kumar, S., 2015. Avian Paramyxovirus: A Brief Review. Transboundary and emerging diseases.

Hoogstraal, H., Kaiser, M.N., Traylor, M.A., Guindy, E., Gaber, S., 1963. Ticks (Ixodidae) on birds migrating from Europe and Asia to Africa 1959-61. Bull World Health Organ 28, 235-262.

Krauss, S., Obert, C.A., Franks, J., Walker, D., Jones, K., Seiler, P., Niles, L., Pryor, S.P., Obenauer, J.C., Naeve, C.W., Widjaja, L., Webby, R.J., Webster, R.G., 2007. Influenza 
in migratory birds and evidence of limited intercontinental virus exchange. PLoS pathogens 3, 1684-1693.

Levin, II, Zwiers, P., Deem, S.L., Geest, E.A., Higashiguchi, J.M., Iezhova, T.A., JimenezUzcategui, G., Kim, D.H., Morton, J.P., Perlut, N.G., Renfrew, R.B., Sari, E.H., Valkiunas, G., Parker, P.G., 2013. Multiple lineages of Avian malaria parasites (Plasmodium) in the Galapagos Islands and evidence for arrival via migratory birds. Conserv Biol 27, 1366-1377.

Lundstrom, J.O., Pfeffer, M., 2010. Phylogeographic structure and evolutionary history of Sindbis virus. Vector borne and zoonotic diseases 10, 889-907.

Malkinson, M., Banet, C., Weisman, Y., Pokamunski, S., King, R., Drouet, M.T., Deubel, V., 2002. Introduction of West Nile virus in the Middle East by migrating white storks. Emerg Infect Dis 8, 392-397.

Miller, P.J., Kim, L.M., Ip, H.S., Afonso, C.L., 2009. Evolutionary dynamics of Newcastle disease virus. Virology 391, 64-72.

Muzyka, D., Pantin-Jackwood, M., Stegniy, B., Rula, O., Bolotin, V., Stegniy, A., Gerilovych, A., Shutchenko, P., Stegniy, M., Koshelev, V., Maiorova, K., Tkachenko, S., Muzyka, N., Usova, L., Afonso, C.L., 2014. Wild Bird Surveillance for Avian Paramyxoviruses in the Azov-Black Sea Region of Ukraine (2006 to 2011) Reveals Epidemiological Connections with Europe and Africa. Appl Environ Microbiol 80, 5427-5438.

Nayak, B., Nayak, S., Paldurai, A., Kumar, S., De Nardi, R., Terregino, C., Collins, P.L., Samal, S.K., 2013. Evaluation of the genetic diversity of avian paramyxovirus type 4. Virus Res 171, 103-110.

Olsen, B., Duffy, D.C., Jaenson, T.G., Gylfe, A., Bonnedahl, J., Bergstrom, S., 1995. Transhemispheric exchange of Lyme disease spirochetes by seabirds. J Clin Microbiol 33, 3270-3274.

Panda, A., Huang, Z.H., Elankumaran, S., Rockernann, D.D., Samal, S.K., 2004. Role of fusion protein cleavage site in the virulence of Newcastle disease virus. Microb Pathogenesis 36, $1-10$.

Parthiban, M., Kaliyaperumal, M., Xiao, S., Nayak, B., Paldurai, A., Kim, S.H., Ladman, B.S., Preskenis, L.A., Gelb, J., Jr., Collins, P.L., Samal, S.K., 2013. Complete genome sequence of an avian paramyxovirus type 4 from north america reveals a shorter genome and new genotype. Genome announcements 1.

Peeters, B.P.H., de Leeuw, O.S., Koch, G., Gielkens, A.L.J., 1999. Rescue of Newcastle disease virus from cloned cDNA: Evidence that cleavability of the fusion protein is a major determinant for virulence. J Virol 73, 5001-5009.

Ramey, A.M., Reeves, A.B., Ogawa, H., Ip, H.S., Imai, K., Bui, V.N., Yamaguchi, E., Silko, N.Y., Afonso, C.L., 2013. Genetic diversity and mutation of avian paramyxovirus serotype 1 (Newcastle disease virus) in wild birds and evidence for intercontinental spread. Arch Virol 158, 2495-2503.

Ramey, A.M., Reeves, A.B., Sonsthagen, S.A., TeSlaa, J.L., Nashold, S., Donnelly, T., Casler, B., Hall, J.S., 2015a. Dispersal of H9N2 influenza A viruses between East Asia and North America by wild birds. Virology 482, 79-83.

Ramey, A.M., Schmutz, J.A., Reed, J.A., Fujita, G., Scotton, B.D., Casler, B., Fleskes, J.P., Konishi, K., Uchida, K., Yabsley, M.J., 2015b. Evidence for intercontinental parasite exchange through molecular detection and characterization of haematozoa in northern 
pintails (Anas acuta) sampled throughout the North Pacific Basin. International journal for parasitology. Parasites and wildlife 4, 11-21.

Senne, D., 2008. Virus propagation in embryonating eggs, in: Dufour-Zavala, L. (Ed.), A laboratory manual for the isolation, identification, and characterization of avian pathogens, 5th ed. American Association of Avian Pathologists, Jacksonville, pp. 204208.

Smith, M.M., Ramey, A.M., 2015. Prevalence and genetic diversity of haematozoa in South American waterfowl and evidence for intercontinental redistribution of parasites by migratory birds. International journal for parasitology. Parasites and wildlife 4, 22-28.

Tallman, E.J., Corkum, K.C., Tallman, D.A., 1985. The trematode fauna of 2 intercontinental migrants: Tringa solitaria and Calidris melanotos (Aves, Charadriiformes). Am Midl Nat 113, 374-383.

Tamura, K., Stecher, G., D., P., Filipski, A., Kumar, S., 2013. MEGA6: Molecular Evolutionary Genetics Analysis Version 6.0. Mol Biol Evol 30, 2725-2729.

Wallmenius, K., Barboutis, C., Fransson, T., Jaenson, T.G., Lindgren, P.E., Nystrom, F., Olsen, B., Salaneck, E., Nilsson, K., 2014. Spotted fever Rickettsia species in Hyalomma and Ixodes ticks infesting migratory birds in the European Mediterranean area. Parasites \& vectors $7,318$.

Warke, A., Stallknecht, D., Williams, S.M., Pritchard, N., Mundt, E., 2008. Comparative study on the pathogenicity and immunogenicity of wild bird isolates of avian paramyxovirus 2 , 4, and 6 in chickens. Avian Pathol 37, 429-434.

Wille, M., Huang, Y.Y., Robertson, G.J., Ryan, P., Wilhelm, S.I., Fifield, D., Bond, A.L., Granter, A., Munro, H., Buxton, R., Jones, I.L., Fitzsimmons, M.G., Burke, C., Tranquilla, L.M., Rector, M., Takahashi, L., Kouwenberg, A.L., Storey, A., Walsh, C., Hedd, A., Montevecchi, W.A., Runstadler, J.A., Ojkic, D., Whitney, H., Lang, A.S., 2014. Evaluation of Seabirds in Newfoundland and Labrador, Canada, as Hosts of Influenza A Viruses. J Wildl Dis 50, 98-103.

Zohari, S., 2013. Avian Paramyxoviruses Serotype 1 to 10, in: Munir, M. (Ed.), Mononegaviruses of veterinary importance. Volume I: Pathobiology and molecular diagnosis, 1st ed. CABI Publishers, Boston, pp. 15-37. 


\section{Primers used in the study}

Table 1.

\begin{tabular}{llll}
\hline \multicolumn{2}{l}{ Name } & Sequence & designer/source \\
\hline A & APMV4_F_fwd & AGTTGATTGGGTGTCTAAAC & this study \\
B & p5490 (antisense) & CCCCACTGAGACACTTGACTAACT & Nayak et al. 2013 \\
C & p5340 (sense) & TCAATAGGGATGGTGGACTTTA & Nayak et al. 2013 \\
D & p6239 (antisense) ABR & ACCTTCCCCACCCTACCATGC & Nayak et al. 2013; modified in this study \\
E & APMV4_HN59-81R & ACTTCTGTTGACTTCTCTTGGTA & Nayak et al. 2008 \\
& (antisense) & &
\end{tabular}

Primer combinations used: A:B (5' of $\mathrm{F}$ gene sequence) in conjunction with $\mathrm{C}: \mathrm{D}$ and/or $\mathrm{C}: \mathrm{E}$ (3' of $\mathrm{F}$ gene sequence) RT-PCR Parameters: $30 \mathrm{~min}$ at $50^{\circ} \mathrm{C}$, followed by $15 \mathrm{~min}$ at $95^{\circ} \mathrm{C}$ and 40 cycles of $45 \mathrm{sec}$ at $94^{\circ} \mathrm{C}, 30 \mathrm{sec}$ at $55^{\circ} \mathrm{C}$ and $1 \mathrm{~min} 45 \mathrm{sec}$ at $72^{\circ} \mathrm{C}$, followed by a final 10 min extension at $72^{\circ} \mathrm{C}$ 


\section{Figure legends}

Figure 1.

Maximum likelihood phylogeny based on the General Time Reversible model using 1,000

bootstrap replicates, values $\geq 50$ are shown, for the complete open reading frame $(1,701 \mathrm{nts})$ of

avian paramyxovirus serotype 4 fusion genes. The tree with the highest log likelihood

$(-7,001.4113)$ is shown. Initial tree(s) for the heuristic search were obtained by applying the

Neighbor-Joining method to a matrix of pairwise distances estimated using the Maximum

Composite Likelihood (MCL) approach. The analysis involved 69 nucleotide sequences.

GenBank Accession numbers and strain names for isolates sequenced as a part of this study are

bold. Continental origins for isolate samples are identified as follows: Europe = open square,

Asia $=$ darkened squared, North America $=$ open circle , and Africa $=$ darkened circle . Major

clades referenced in this study are bracketed and labeled: A-E. The number of base (NT) and

amino acid (AA) differences per site as averaged across all sequence pairs between groups is

shown (inset). The analysis involved 67 nucleotide sequences. Codon positions included were

1 st+2nd+3rd+Noncoding. There were a total of 1,701 positions in the final dataset. Evolutionary

analyses were conducted in MEGA6 
KT732297 APMV-4/Anas sp./Japan/10KI294/2010

KT732298 APMV-4/Anas sp./Japan/10KI309/2010

I KT732296 APMV-4/Anas sp./Japan/10KI292/2010

GT732295 APMV-4/Anas sp./Japan/10KI290/2010

GT732294 APMV-4/Anas sp./Japan/10KI287/2010

KT732299 APMV-4/Anas sp./Japan/10KI318/2010

$6 \mid$ KT732300 APMV-4/Anas sp./Japan/10KI321/2010

66 KT732292 APMV-4/green-winged teal/Japan/10EY0036/2010

KT732302 APMV-4/Anas sp./Japan/10U00481/2010

KT732304 APMV-4/Anas sp./Japan/10UO0510/2010

KT732305 APMV-4/Anas sp./Japan/10U00689/2010

KT732311 APMV-4/Anas sp./Japan/9U00180/2009 KC439346 APMV4/duck/China/G302/2012

\begin{tabular}{lll} 
A-B & 0.025 & 0.014 \\
\hline A-D & 0.104 & 0.039
\end{tabular}

$\begin{array}{lll}\text { A-D } & 0.104 & 0.039\end{array}$

$\begin{array}{lll}\text { A-E } & 0.143 & 0.049\end{array}$

B-C $\quad 0.026 \quad 0.012$

$\begin{array}{lll}B-D & 0.109 & 0.037\end{array}$

$\begin{array}{lll}B-E & 0.141 & 0.048\end{array}$

C-D $\quad 0.098 \quad 0.032$

$\begin{array}{lll}C-E & 0.143 & 0.046\end{array}$

D-E $\quad 0.145 \quad 0.046$

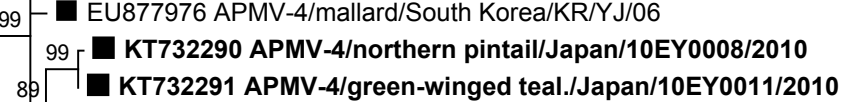

KT732309 APMV-4/Anas sp./Japan/8K10083/2008

$\$ 9$ KT732310 APMV-4/Anas sp./Japan/8K10200/2008

8499 KT732301 APMV-4/Anas sp./Japan/10UO0441/2010

KT732303 APMV-4/Anas sp./Japan/10U00499/2010

99 KT732312 APMV-4/Anas sp/Japan/9U00234/2010

[D KT732344 APMV- 4/White-Fronted Goose/Syvaske/Ukraine/6-15-03/2014

$99\left[\begin{array}{l}\text { KT732344 APMV- 4/White-Fronted Goose/Syvaske/Ukraine/6-15-03/2014 } \\ \text { KT732343 APMV-4/Ruddy Shelduck/Askania-Nova/Ukraine/5-1-03/2014 }\end{array}\right.$

$9857 \square$ KT732342 APMV-4/Ruddy Shelduck/Askania-Nova/Ukraine/4-1-03/2014 C KF851267 APMV-4/teal/Djankoy/Ukraine/9-17-11/2010

57 KT732341 APMV-4/White-Fronted Goose/Vasylivka/Ukraine/11-15-03/2014

口 KT732338 APMV-4/Garganey/Davydivka/Ukraine/5-11-08/2013

100 KT732337 APMV-4/Garganey/Davydivka/Ukraine/4-11-08/2013

95 C KT732336 APMV-4/mallard/Ozerane/Ukraine/3-20-11/2011

C KT732345 APMV-4/mallard/Askania-Nova/Ukraine/507-11-12/2014

100

KT732335 APMV-4/mallard/Krasnoperecopsk/Ukraine/9-10-10/2010

KF851266 APMV-4/starling/Medvedkovo/Ukraine/5-24-12/2010

84 $\square$ KT732339 APMV-4/mallard/Novomychalivka/Ukraine/9-23-12/2010

86 JX133079 APMV-4/Egyptian goose/South Africa/N1468/2010 $\square$ JX501910 APMV-4/duck/ttaly/3670/06

- APMV-4/mallard/Ermacovo/Ukraine/14-11-01/2012

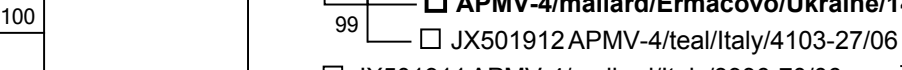

— JN571485 APMV4/mallard/Belgium/15129/07

64 JX501913 APMV-4/mallard//taly/4284-20/06

97 JX501914 APMV-4/mallard/taly/4523-4/06

KT732293 APMV-4/Anas sp./Japan/10KI182/2010

- FJ177514 APMV-4/duck/Hong kong/D3/75

99 O KT732313 APMV4/mallard/Minnesota/USA/A107-3119/2007

CO KT732316 APMV4/mallard/Minnesota/USA/AI07-4424/2007

100 O KT732330 APMV4/American green-winged teal/Texas/USA/Al13-334/2013

100 O KT732308 APMV4/northern pintail/Alaska/USA/2013-0714/2013

78 KT732306 APMV4/northern pintail/Alaska/USA/2011-0935/2011

99 O KT732307 APMV4/emperor goose/Alaska/USA/2011-0941/2011

-O KT732333 APMV4/American green-winged tea/North Carolina/USA/NC671-045/2005

O KT732334 APMV4/wood duck/North Carolina/USA/NC671-064/2005

78. O KT732317 APMV4/mallard/Minnesota/USA/A107-4781/2007

98 O KT732325 APMV4/mallard/Minnesota/USA/AI08-5495/2008 - O KT732318 APMV4/mallard/Minnesota/USA/A107-4998/2007

KT732329 APMV4/American green-winged teal/Minnesota/USA/Al12-5053/2012 O KT732331 APMV4/mallard/Minnesota/USA/Al13-4187/2013

_O KT732332 APMV4/mallard/Minnesota/USA/Al13-4217/2013

O KT732323 APMV4/mallard/Minnesota/USA/AI08-3518/2008

O KT732326 APMV4/mallard/Minnesota/USA/Al08-5497/2008

O KT732327 APMV4/mallard/Minnesota/USA/Al08-5507/2008

O KT732328 APMV4/mallard/Minnesota/USA/A108-5553/2008

-O KT732324 APMV4/northern shoveler/Louisiana/USA/Al08-5187/2008

O JX987283 Avian paramyxovirus 4 strain APMV-4/duck/Delaware/USA/549227/2010 O KT732319 APMV4/mallard/Minnesota/USA/AI07-5009/2007 O KT732321 APMV4/mallard/Minnesota/USA/AI07-5056/2007 O KT732322 APMV4/mallard/Minnesota/USA/A107-5069/2007

KT732320 APMV4/mallard/Minnesota/USA/A

5 KT732314 APMV4/mallord/MinnesotuSA/A107-3630/2007

O KT732315 APMV4/mallard/Minnesota/USA/AI07-4266/2007 